\title{
Ações antrópicas ocorridas no bairro Maracanã e a avaliação de impactos ambientais em Santarém - PA
}

Anthropic actions in the Maracanã neighborhood and the evaluation of environmental impacts in Santarém - PA

Acciones antrópicas en el barrio de Maracanã y evaluación de los impactos ambientales en Santarém - PA

\section{Resumo}

A urbanização é essencial à qualidade de vida das populações, todavia, ela é sempre acompanhada de impactos ambientais positivos e negativos. O objetivo dessa pesquisa foi avaliar os impactos ambientais causados no bairro Maracanã, Santarém, Pará. O método aplicado foi o da investigação foto analítica, com abrangência quantiqualitativa e natureza aplicada. Os dados primários foram obtidos no local, via fotografias, e o secundários em links acadêmicos de acesso livre, para seleção das literaturas publicadas entre 2012 e 2021, com apenas uma literatura pioneira (1994). Os dados obtidos e analisados foram alocados em uma matriz adaptada de Leopold, onde se efetuou os cálculos de magnitude e importância da cada um dos três meios ambientais em razão de operações em andamento nesse bairro: terraplanagem, escavação e pavimentação asfáltica. Para o meio físico o menos impactado (-197), identificou-se que o Elemento ambiental solo, está em progressão o processo de compactação (0.9). O antrópico (-4) é o mais impactados dos três meios analisados. Dos 30 componentes ambientais mensurados, a oferta de empregos apresentou o mais elevado grau de impacto a partir da renda familiar (-2). Em face desses dados, foram sugeridas aplicações de medidas mitigatórias corretivas em caráter de urgência para evitar danos maiores à comunidade e ao ambiente, ou seja, no bairro Maracanã.

Palavras-chave: Escavações; Infraestrutura urbana; Pavimentação asfáltica.

\footnotetext{
Abstract

Urbanization is essential to the population's quality of life, but positive and negative environmental impacts always accompany it. The objective of this research was to evaluate the environmental impacts caused in the neighborhood
} 
Maracanã, Santarém, Pará. The method applied was photo-analytical research, with a quantitative and qualitative scope, and applied nature. The primary data obtained on-site, via photographs, and the secondary in open-access academic links to select the works of literature published between 2012 and 2021, with only one pioneer literature (1994). The data obtained and analyzed were allocated in a matrix adapted from Leopold, where the calculations of magnitude and importance of each of the three environmental media made due to ongoing operations in this neighborhood: earthworks, excavation, and asphalt paving. For the physical environment, the least impacted (-197), identified that the soil environmental element is undergoing a compaction process (0.9). The anthropic element (-4) is the most impacted of the three analyzed environments. Of the 30 environmental components measured, the job offer presented the highest impact from the family income (-2). Because of these data, corrective mitigation measures suggested as a matter of urgency to avoid more considerable damage to the community and the environment, that is, in the Maracanã neighborhood.

Keywords: Excavations; Urban infrastructure; Asphalt paving.

\section{Resumen}

La urbanización es esencial para la calidad de vida de la población, pero siempre va acompañada de impactos ambientales positivos y negativos. El objetivo de esta investigación fue evaluar los impactos ambientales causados en el distrito de Maracanã, Santarém, Pará. El método aplicado fue el de la investigación foto analítica, de alcance cuantitativo y de carácter aplicado. Los datos primarios se obtuvieron in situ, a través de fotografías, y los secundarios en enlaces académicos de libre acceso, por selección de las literaturas publicadas entre 2012 y 2021, con una sola literatura pionera (1994). Los datos obtenidos y analizados se asignaron en una matriz adaptada de Leopold, en la que se calculan la magnitud y la importancia de cada uno de los tres medios ambientales debidos a las operaciones en curso en este barrio: movimientos de tierra, excavación y pavimentación de asfalto. Para el entorno físico el menos impactado (-197), se identificó que el elemento ambiental del suelo es en progresión el proceso de compactación $(0,9)$. El antrópico (-4) es el más impactado de los tres entornos analizados. De los 30 componentes ambientales medidos, la oferta de trabajo presentó el mayor grado de impacto de la renta familiar (-2). A la vista de estos datos, se sugirieron medidas correctivas de mitigación con carácter de urgencia para evitar mayores daños a la comunidad y al medio ambiente, es decir, al barrio de Maracanã.

Palabras clave: Excavaciones; Infraestructura urbana; Pavimentación de asfalto.

\section{Introdução}

Ação antrópica é a maneira com que o ser humano se apropria dos recursos naturais, já que a primeira relação entre eles, ocorre em função do trabalho, ou seja, a natureza fornece os insumos e o homem os utiliza para produção de bens de que necessita (Lima, 2016; Giacometti \& Pilão, 2018). Todavia, as formas de exploração na relação homem-trabalho-natureza, evoluiu de tal forma que, no século atual, a necessidade de insumos acelerou o processo de exploração dos recursos ainda disponíveis, porém, sem o caráter infinito e com rastros de alterações e degradações ambientais severas (Carvalho et al., 2021; Kaiser et al.,2017).

Sobre esse tipo de ação, ela pode ocorrer de várias formas: 1) Nos ambientes de lazer como, por exemplo, as praias. Em geral, elas ocorrem em escalas sazonais (período de férias) e, como a maioria deles estão associadas aos oceanos, o problema se agrava mais. Nesse caso, duas ações são evidentes: o descarte inadequado de resíduos sólidos e a poluição dos corpos hídricos devido a ineficiência/ausência do saneamento básico (Carneiro \& Terra, 2020; Hatje et al., 2018). As atividades rurais como, o cultivo agrícola provoca pressões sobre as áreas florestadas que, quando perdem a cobertura vegetal, determinam também a perda de habitat e a não formação dos chamados corredores ecológicos, além de comprometer o contexto histórico cultural da local onde ocorreu a ação antrópica (Lopes \& Longo, 2020; Rosa et al., 2021).

Todavia, as ações antrópicas não ocorrem apenas no contexto rural, elas também ocorrem nos espaços urbanos que, em função do crescimento populacional provoca expansão urbana e incrementa a atividade imobiliária que, sem uma eficiente gestão urbana, gera impactos ambientais como, a formação de ilhas de calor (Amorim, 2020; Souza \& Mesquita, 2017).

Outra ação antrópica atrelada a urbanização que provoca impacto ambiental de elevadas consequências ao meio ambiente, está atrelado as ocupações das Áreas de Proteção Ambiental (APP), especialmente em municípios que são atravessados ou se originaram às margens de corpos hídricos, de forma irregular (Bezerra et al., 2021; Silva et al., 2019). As 
aberturas de rodovias são exemplos de ações antrópicas cujos impactos negativos (podem elevar os riscos de quantificação dos focos de calor; poluição hídrica) superam os chamados positivos (Ex.: empregos gerados). Na rodovia BR-230, tem-se municípios cujos corpos hídricos eram utilizados para recreação, abastecimento de comunidade que, após a implantação dessa rodovia, não prestam mais esses serviços ecossistêmicos (Araújo et al., 2020; Silva, P. \& Silva, M, 2020)

Quando a implantação de infraestrutura urbana (Ex.: pavimentação asfáltica, implantação de rede para coleta de efluentes domésticos) chegam a bairros periféricos dos municípios, também há geração de ações antrópicas impactantes, e que podem provocar impactos como alagamentos de vias e artérias, devido à ausência de galerias e janelas pluviométricas para captação de água das chuvas (Corrêa et al., 2018; Matos et al., 2019). Um dos desafios que se opõe a ação antrópica dessa e de outras naturezas, é a necessidade de áreas verdes urbanas porque elas podem evitar enchentes, inundações e alagamentos em bairros onde a cota altimétrica é baixa já que, após a pavimentação asfáltica, ocorre uma diminuição na capacidade de infiltração da água no solo (Ono et al., 2017; Silveira et al., 2019)

Consequentemente, a avaliação de impactos ambientais, associa-se a antropogeomorfologia para análise das atividades humanas e a transformação do relevo geográfico e das modificações de propriedades físico-químicas do solo (Stefanuto et al., 2017; Scalamato et al., 2019). Uma das ações antrópicas que altera o relevo é a pavimentação que, atualmente, é importante à população porque permite excelente locomoção, seja, a pé ou motorizado. Um projeto dessa ação, seja asfáltica ou cimentícia, bem estruturado e executado, pode evitar impactos ambientais impactos, especialmente os negativos, tanto ao ambiente quanto a qualidade de vida da comunidade, incluam-se os trabalhadores que labutam nessa atividade. Então, as modificações ambientais interferem na saúde humana (Lima, 2017; Lopes, 2008).

Já a Avaliação de Impacto Ambiental (AIA), com seis ferramentas à disposição dos avaliadores, dentre elas, tem-se a Matriz de Interação como a de Leopold ou a de Fisher Davis, é uma necessidade legislativa para a concessão de licenças ambientais àquelas atividades econômicas ou não que, a partir da elaboração do projeto de implantação, funcionamento e/ou encerramento das atividades, provoquem alterações no meio ambiente e nos recursos naturais ali dispostos, e que essa avaliação poderá prever ou supor a ocorrência delas, independentemente do método utilizado para tal (Martins \& Carmo Júnior, 2018; Rosa, 2019).

A relação causa-efeito advinda das ações antrópicas são problemas que necessitam de avaliações contínuas para que se mitigue os impactos por elas causados. Tal argumento justificou essa pesquisa, bem como incrementou a relevância dela porque coletou dados reais acerca de melhorias na infraestrutura urbana e, com isso, contribuiu para a elaboração do objetivo: avaliar os impactos causados pela terraplanagem, implantação de rede de captação de efluentes domésticos e pavimentação asfáltica em Santarém, Pará.

\section{Metodologia}

\subsection{Fisiografia do município}

O município de Santarém (Figura 1), a "Pérola do Tapajós", está localizado na região oeste do estado do Pará, possui uma área geográfica equivalente a 17.898,389 km2, população estimada em 3089.339 habitantes. Dentre as infraestruturas urbanas básicas, apresenta uma cobertura para a coleta de efluentes domésticos em $38 \%$ dos domicílios, a arborização equivale a $43 \%$, e apenas $8 \%$ das vias urbanas apresenta bueiros, calçadas, pavimentação e passeio, vale ressaltar que estes dados são inerentes a 2010, já que o novo censo ainda não foi realizado. O clima é classificado com equatorial: Am (IBGE, 2020). 
Figura 1. Mapa de localização do município de Santarém, Pará.

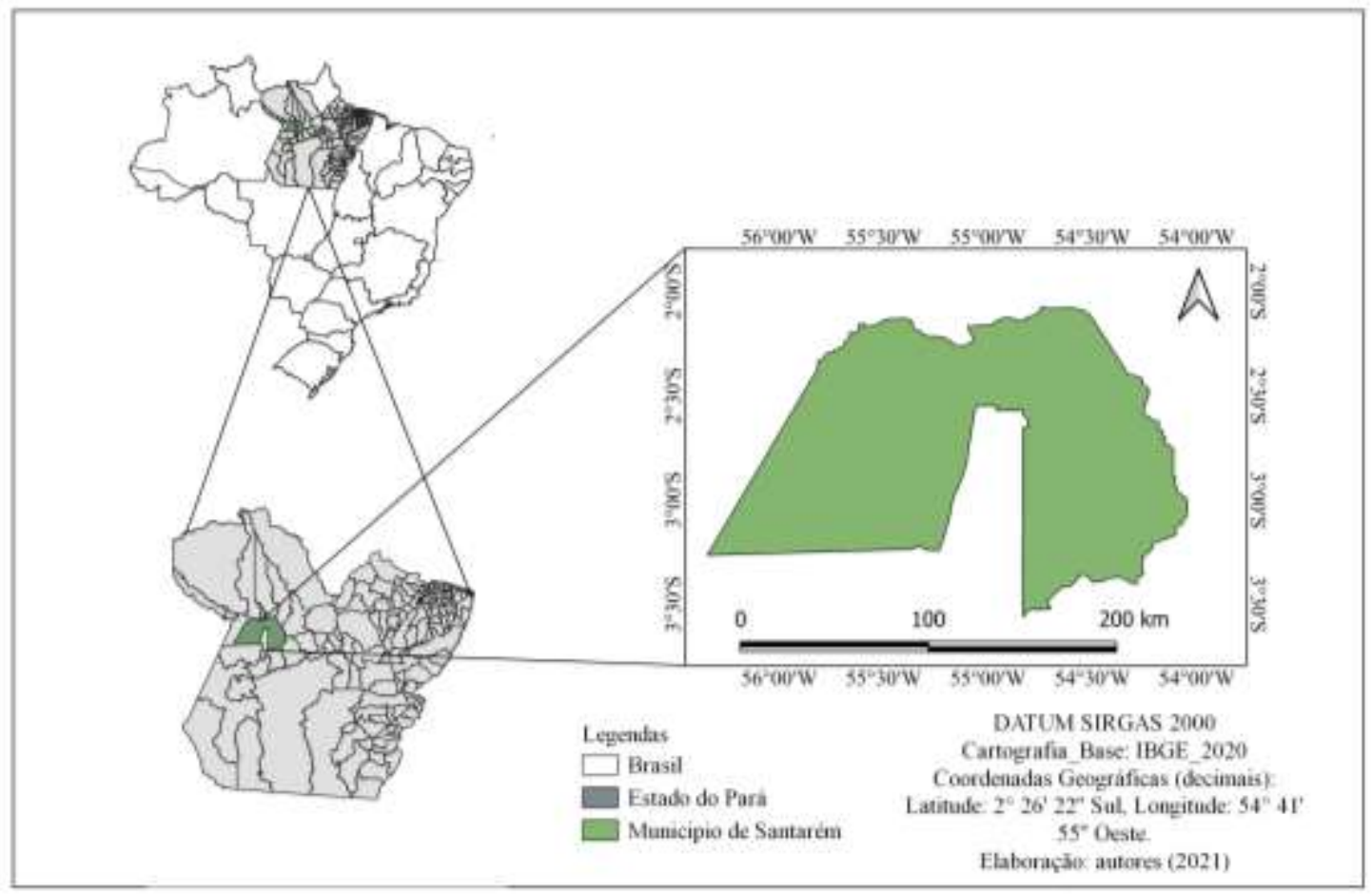

Fonte: Autores (2021).

A posição "privilegiada" dessa município, conforme verificado na Figura 1, o coloca em contado com o rio Tapajós, o que favorece a economia, o transporte, e o turismo. Todavia, a urbanização ainda não é frequente, tanto que o bairro maracanã, cujas coordenadas geográficas são: 2²7'02.3"s 5442'03.3"w), foi assim denominado em função dos pássaros com o mesmo nome que frequentavam em busca de alimentos a área onde hoje ele está localizado (Figura 2a), ou seja, a oeste do município de Santarém (UFOPA, 2020). Atualmente, encontra-se em obras (Figura 2b) para implantação de infraestrutura adequada.

Figura 2. a) Bairro maracanã (em verde); b)Vista latero-frontal de acesso ao bairro Maracanã localizado a oeste do município de Santarém, Pará.
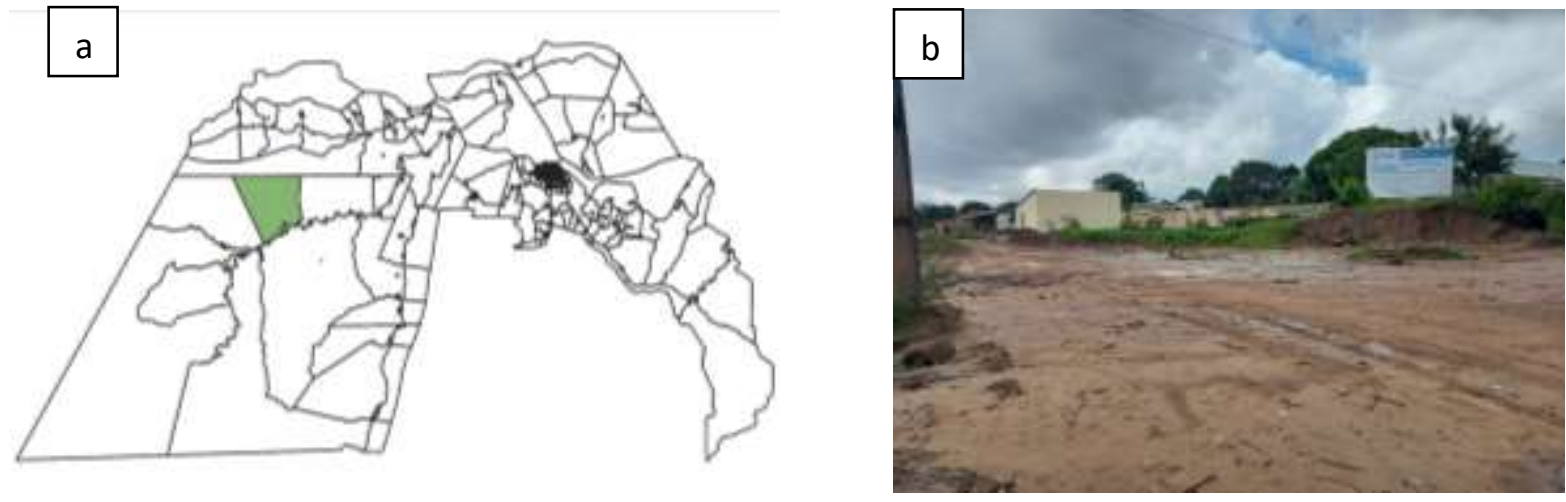

Fonte: Autores (2021).

Tal ação, causa impactos ambientais, nesse contexto, ele foi selecionado para a verificação de ocorrências das ações antrópicas de terraplanagem, implantação de rede de captação de efluentes domésticos e pavimentação asfáltica, Porém, a 
declividade média $\left(D_{\operatorname{máx}}=14 \mathrm{~m} ; D_{\min }=6 \mathrm{~m} ; \bar{x}=10 \mathrm{~m}\right)$ nas vias de fluxo duplo e simples cuja direção final é sempre o rio Tapajós, ao sul desse local, e a 1.340 m de distância (Figura 3).

Figura 3. a) Vista superior da delimitação do bairro objeto dessa pesquisa (traço em vermelho). Santarém, Pará.

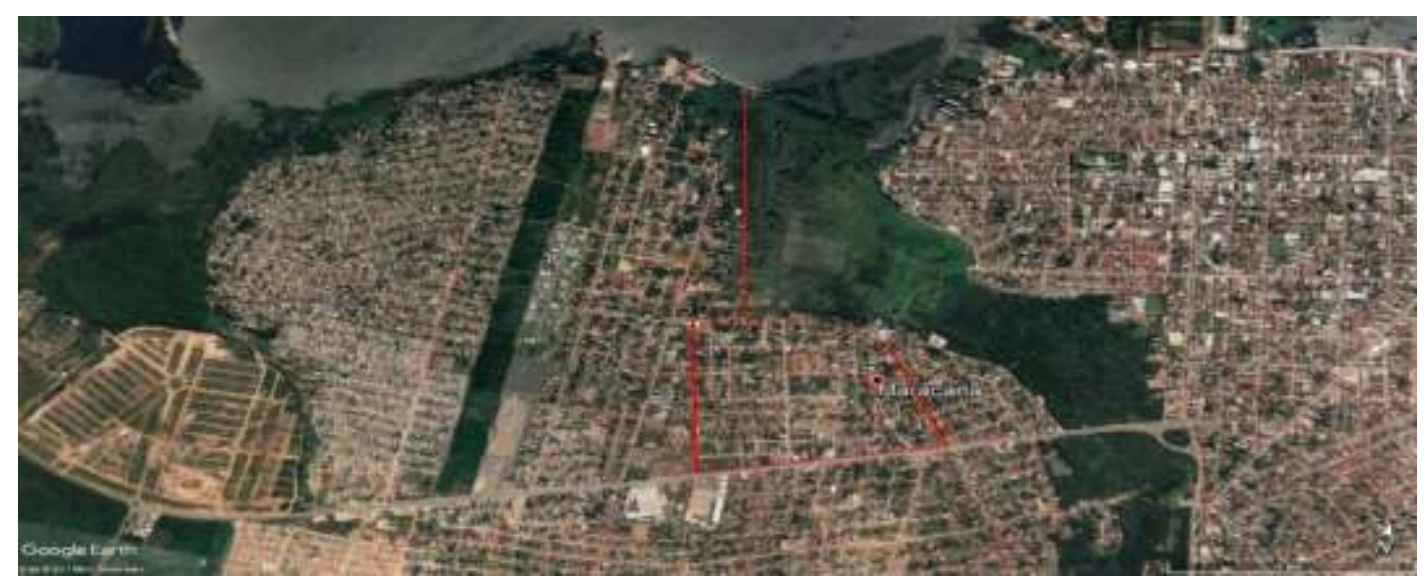

Fonte: adaptada pelos autores a partir do Google Earth (2021).

Na Figura 3, a linha vertical vermelha indica a distância que há entre o bairro em estudo (Figura 4a) e a orla marítima do município, é uma das razões para a realização das obras de pavimentação (Figura b) implantação de rede coletora de efluentes (Figura 4c), e Terraplanagem (Figuras 4d;e), além da coleta de resíduos sólidos (Figura 4f) porque facilitará o acesso de banhistas e turistas até esse local.

Figura 4. a) Local de início da terraplanagem; b) implantação da placa evidenciando a obra em si, onde já se observa a formação de poças d'água; c) terraplanagem concluída devido a coloração diferente da camada superficial do solo, sem declive, com disposição das anilhas de concreto para implantação da rede de captação de efluentes domésticos; d; e) via com acentuado declive, após chuva. Nota-se o solapamento e perda de massa de solo marginal; f) disposição final de resíduos sólidos com posterior queima.

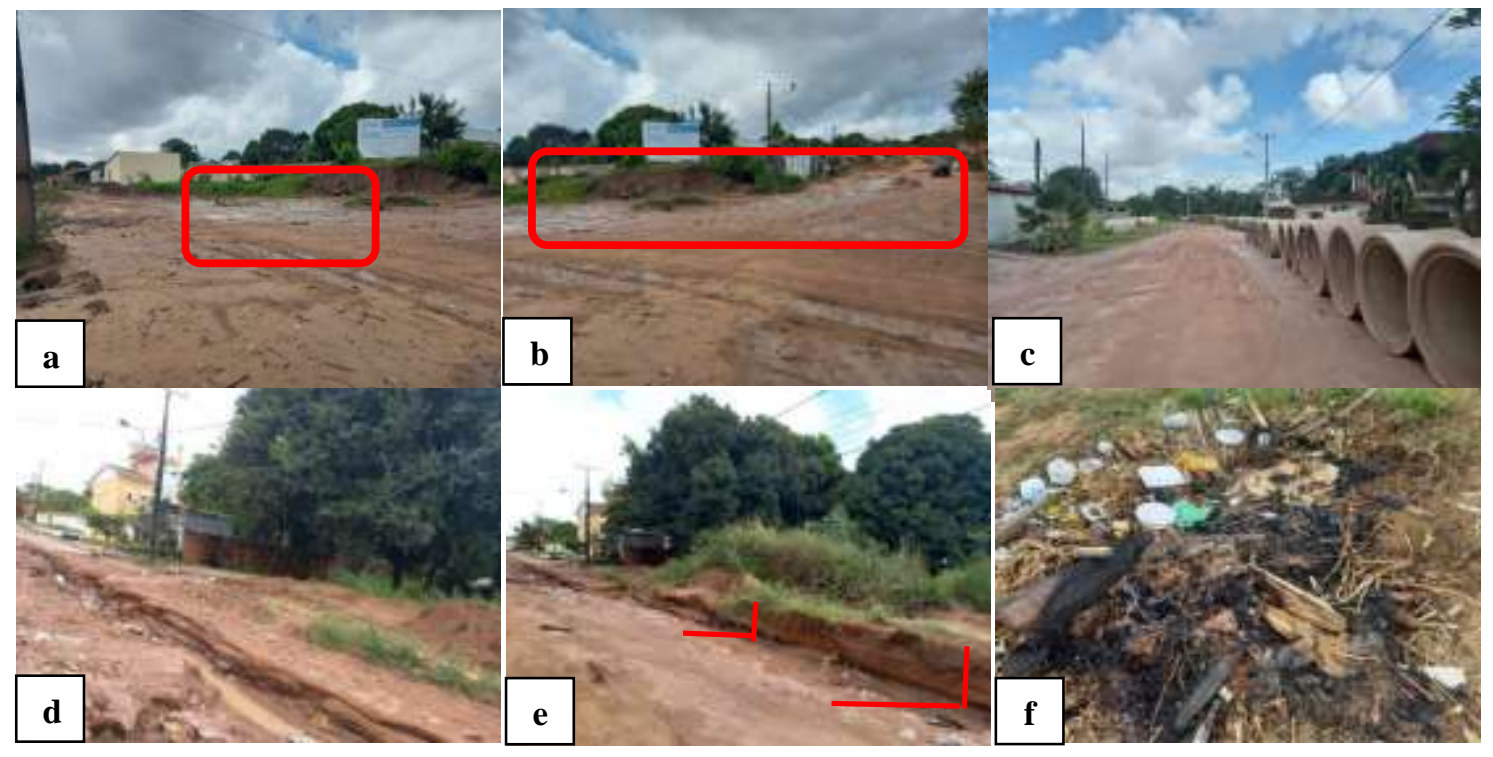

Fonte: Autores (2021).

As ações de terraplanagem, implantação de rede captação de efluentes domésticos e pavimentação asfáltica geram impactos ambientais. Deste modo, urge à necessidade de identificar os impactos ambientais causados por essas ações, nesse 
bairro, no município de Santarém, Estado do Pará. Para tal, foi elaborado o memorial fotográfico (Figura 4), com visita in sito efetuada pela discente Luiza Helena Silva de Souza.

O método empregado nessa pesquisa foi o investigativo, com abrangência quantitativa e qualitativa. Em relação a investigação, Sorte e Coêlho (2019), sintetizaram que a investigação e estudo são minudentes e sistemáticos, detalhado e que forneça mais conhecimento acerca de um determinado tema. Nesse caso, a relação causa-efeito da infraestrutura urbana em implantação no bairro Maracanã. Já a abrangência, foi baseada no descrito por Pereira et al. (2018) que afirmaram ser factível o emprego de métodos que envolvam a quantidade e a qualidade como é efetuado na AIA. Para melhor empregabilidade desse método, foram utilizadas cinco etapas (Figura 5)

Figura 5. Etapas desenvolvidas para a aplicação do método dessa pesquisa.

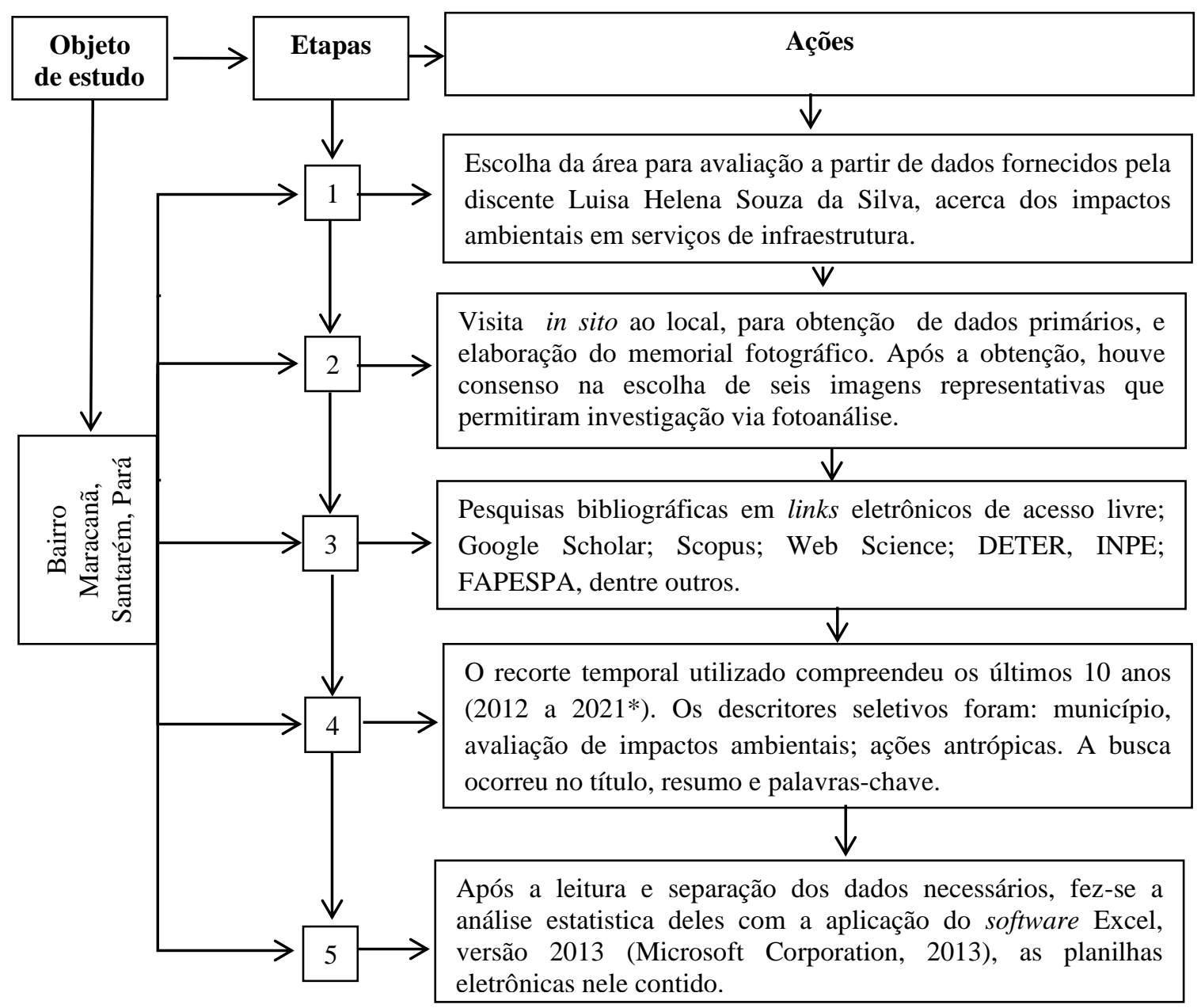

*Excetuem-se as legislações ambientais brasileiras e duas literaturas pioneiras: Mori (1994); Stam (2003). Fonte: Autores (2021).

Após a obtenção das imagens, fez-se a adaptação da matriz de Leopold (Quadro 1) devido a relação causa-efeito que ela permite avaliar, para análise, valoração e proposição de medidas mitigatórias aos impactos ambientais identificados. Para o cálculo da magnitude, Stamm (2003), expressa quantitativamente o impacto, além de indicar o grau de alteração ocorrida no parâmetro ambiental sujeito a análise em, finalmente, permitir a qualificação dele) e da importância (trata-se de uma ponderação ao impacto quando se quer verificar o que ocorreu com o fator ambiental analisado e compará-los com outros impactos), foram utilizadas Equações (1;2), de acordo com o proposto por Morales et al. (2015). 


$$
M=(A+D+R) * N(1)
$$

Onde: $M=$ Magnitude; $A=$ Abrangência; $D=$ Duração; $R=$ Reversibilidade; $N=$ Natureza (+/-)

$$
I=(3 I+E+2 A+T+2 D+R) * N(2)
$$

Onde: $I=$ Intensidade $E=$ Efeito; $A=$ Abrangência; $D=$ Duração; $R=$ Reversibilidade.

Sobre as terminologias aqui empregadas, a magnitude identifica a intensidade de manifestação de um determinado impacto e como ele pode alterar o ambiente onde ocorre. O atributo é uma característica exclusiva do impacto que permite a descrição dele e ainda a aplicação de valor; componente ambiental é o que se escolhe para avaliar; meio antrópico, é a própria sociedade que se encontra na área, ou ao derredor dela quando da avaliação de impacto ambiental (Sánchez, 2013).

Em relação a qualificação da Magnitude $(\mathrm{M})$ e da Importância (I), foram utilizadas três classificações em função dos valores quantitativos encontrados (Tabela 1). A base para o uso dessa escala foi a partir do preconizado por Morales et al. (2015). O sinais matemáticos que antecedem os numerais cardinais identificam se a natureza do impacto é positiva (+) ou negativa (-)

Tabela 1. Valores e qualificações para Importância e Magnitude dos impactos ambientais identificados no bairro Maracanã, Santarém, Pará.

\begin{tabular}{ccc}
\hline Valores & Qualificação & Valores \\
\hline$\leq+6 \mathrm{a} \geq+10$ & Alta & $\geq-1 \mathrm{a} \leq-5$ \\
$\leq+1$ & Baixa & $\geq-10$ \\
$\leq \pm 2 \mathrm{a} \leq \pm 5$ & Média & $\geq-6 \mathrm{a} \leq-9$ \\
\hline
\end{tabular}

Fonte: Adaptada a partir de Morales et al. (2015).

Para os valores estabelecidos foi adotado aqueles compreendidos entre 1 e 5, de acordo com o preconizado por Fisher e Davies em 1972 (Stamm, 2003), pois efetuou-se a avaliação em duas dimensões: magnitude e importância. A escala empregada foi na ordem diretamente proporcional, ou seja, quanto maior o valor atribuído, maior será o grau do impacto ambiental. Os cálculos que definiram os valores dos componentes de Magnitude e Importância, foi utilizada a Equação 3.

$$
A=\frac{\bar{x}_{v i}+N^{\circ} o \cdot}{\Sigma i \cdot a} \cdot(5+V \cdot A)
$$

Onde: $A=$ Atributo; $\bar{X}_{v, i}=$ Média dos valores acumulados dos impactos nos elementos ambientais em análise, nas três operações; $N^{o} \mathrm{O} .=$ Número de operações; $\Sigma i \cdot a=$ Total de índices analisados; 5 - valor máximo utilizado na escala de Fisher e Davies; V.A = Valor numérico do atributo com base na escala elaborada por Sànchez (2013), ou seja, valores numéricos compreendidos entre 1 e 10 . Os resultados decimais foram arredondados para mais, a partir de 0,49, e para menos, a partir de 0,4 e, quando igual a 0,5 , permanecerá igual.

\section{Resultados e Discussão}

Os dados obtidos e analisados alocados na Matriz indicaram que o meio mais efetivamente impactado foi o antrópico (Quadro 1). 
Quadro 1. Matriz de Interação de Impactos identificados e valorados no Bairro Maracanã, Santarém-Pará

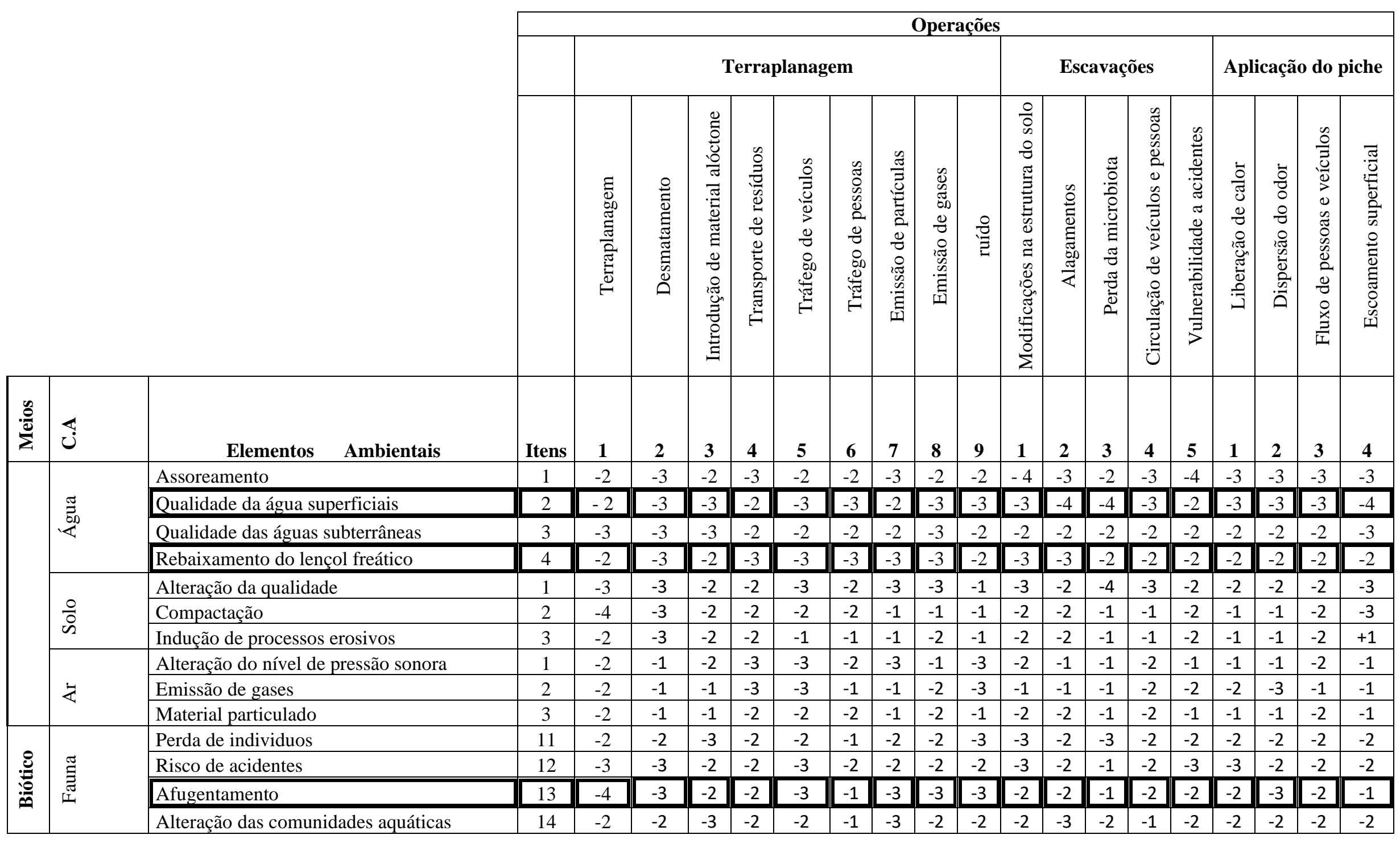




\begin{tabular}{|c|c|c|c|c|c|c|c|c|c|c|c|c|c|c|c|c|c|c|c|c|c|}
\hline & & Alteração da dinâmica populacional & 15 & -3 & -3 & -2 & -2 & -3 & -2 & -3 & -3 & -3 & -3 & -2 & -2 & -2 & -2 & -3 & -3 & -2 & -2 \\
\hline & \multirow{3}{*}{$\frac{\pi}{\frac{\pi}{I}}$} & Perda de individuos & 16 & -3 & -3 & -2 & -2 & -3 & -2 & -3 & -3 & -2 & -3 & -2 & -1 & -2 & -2 & -2 & -3 & -2 & -1 \\
\hline & & Pressão sobre habitats & 17 & -2 & -2 & -3 & -2 & -2 & -2 & -2 & -2 & -2 & -2 & -3 & -2 & -3 & -2 & -2 & -2 & -2 & -3 \\
\hline & & Diminuição da fotossíntese & 18 & -3 & -3 & -2 & -2 & -2 & -2 & -3 & -3 & -1 & -3 & -3 & -2 & -2 & -1 & -3 & -3 & -2 & -2 \\
\hline \multirow{14}{*}{ 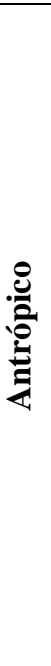 } & \multirow{5}{*}{ 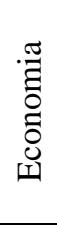 } & Alteração do valor da terra & 19 & +3 & +3 & -2 & -3 & -1 & +3 & +3 & -2 & -1 & -3 & -3 & -2 & -2 & +2 & -2 & -3 & -2 & +3 \\
\hline & & Mudança do uso e ocupação do solo & 20 & +3 & +3 & +2 & -2 & -2 & +2 & +3 & -1 & -1 & -3 & -2 & -2 & -1 & -1 & -2 & -2 & -2 & -2 \\
\hline & & Renda familiar & 21 & +3 & +3 & -2 & -1 & +1 & +2 & +2 & -1 & -1 & -1 & -1 & -2 & -1 & +2 & -2 & -1 & -1 & +3 \\
\hline & & Recolhimento de tributos e encargos sociais & 22 & +3 & +3 & -1 & +1 & +2 & +2 & +2 & -1 & -1 & -1 & +2 & -1 & -1 & +2 & -1 & -1 & -1 & +2 \\
\hline & & Receita das empresas locais e regionais & 23 & +3 & +3 & +1 & +2 & +2 & +2 & +1 & -1 & -1 & -1 & +3 & -1 & -1 & +2 & -1 & -1 & -1 & +3 \\
\hline & \multirow{4}{*}{ 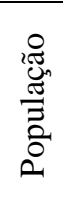 } & Alterações na qualidade de vida & 24 & +3 & +3 & -2 & -2 & -2 & +2 & +3 & -2 & -2 & -2 & -2 & -2 & -1 & +2 & -2 & -2 & -2 & +3 \\
\hline & & Conflitos com moradores e vizinhança & 25 & -2 & -3 & -2 & -1 & -1 & -1 & -1 & -1 & -1 & -1 & -1 & -2 & -1 & -2 & -2 & -1 & -1 & -2 \\
\hline & & Oferta de empregos & 26 & +2 & +2 & +2 & +1 & +2 & +2 & +2 & -1 & -1 & -1 & +2 & -1 & -1 & +2 & -1 & -2 & -2 & +2 \\
\hline & & Demanda de serviços públicos & 27 & +4 & +3 & +2 & +2 & +2 & +2 & +2 & -1 & -1 & -1 & +2 & -1 & -3 & +2 & -1 & -1 & -1 & +3 \\
\hline & \multirow{5}{*}{ 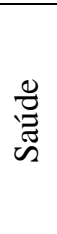 } & Doenças pela geração de resíduos sólidos & 28 & -3 & -3 & -3 & -2 & -2 & -2 & -1 & -2 & -2 & -2 & -1 & -2 & -2 & -2 & -1 & -2 & -2 & -2 \\
\hline & & Doenças pela geração de efluentes líquidos & 29 & -1 & -1 & -2 & -2 & -2 & -3 & -2 & -1 & -1 & -1 & -2 & -3 & -1 & -2 & -1 & -1 & -1 & -3 \\
\hline & & Doenças pela geração de efluentes gasosos & 30 & -2 & -2 & -2 & -2 & -3 & -2 & -2 & -3 & -3 & -1 & -1 & -1 & -1 & -2 & -1 & -3 & -1 & -3 \\
\hline & & & $\sum$ & -27 & -24 & -43 & -43 & -40 & -16 & -20 & -48 & -41 & -61 & -42 & -49 & -48 & -24 & -52 & -54 & -50 & -21 \\
\hline & & & & +8 & +8 & +4 & +3 & +5 & +8 & +8 & -- & -- & -- & +4 & -- & -- & +6 & -- & -- & -- & +6 \\
\hline
\end{tabular}

Legenda: C. A. = Componente Ambiental; E.A = Elementos Ambientais. Elaborado Autores a partir dos dados por eles obtidos (2021).

No Quadro 1, observou-se que ocorreram, nos 30 elementos ambientais analisados, 368 impactos, e a maioria $(n=21 ; 70 \%)$ de natureza negativa. Para terraplanagem, o meio físico apresentou maior valor acumulado (-197); sobre o biótico, o valor acumulado foi menor (-170), o que indica maiores ações impactantes. Já o meio antrópico, apresentou o menor valor acumulado quando comparado aos dois anteriores (-4), o que indica elevado grau de impactação. Acerca da terraplanagem e escavações, já foram efetuados estudos sobre esse tema, por Fonseca et al. (2020) e Silva (2020), este último ocorrido em Manaus - AM, quando da construção do ramal na AM-010, km 32, ao Km 10 da BR - 174, afirmaram que, apesar da grande importância que ela possui em obras de construções civis, os impactos por ela causados são negativos e graves como, por exemplo, retirada de areia, vegetação, elevação de riscos a erosões, dentre outros. 
Quanto a impermeabilidade do solo com piche, Fernandes et al. (2014) e Gouveia (2019), escreveram que uma obra rodoviária acarreta aspectos negativos como a movimentação de maquinário pesado, aumento da poluição atmosféricas casados pelos ligantes do asfalto que ainda provoca diminuição na drenagem urbana.

\section{Meio Físico}

Para terraplanagem, dentre os 11 componentes ambientais analisados, os dados obtidos indicaram que dois deles foram os mais impactados: qualidade das águas superficiais e rebaixamento do lençol freático $(n=-24)$. Sobre as alterações na qualidade das águas, Matos et al. (2019), efetuaram estudos sobre impactos ambientais no Bairro São José, Juazeiro do NorteCE, e Bezerra et al. (2021), no Bairro Serrinha-CE concluiram que os corpos hídricos podem sofrer poluição via precipitações pluviométricas e escoamento superficial, bem como as áreas de balneabilidade, o que corrobora com o identificado no bairro Maracanã, em Santarém, já que ele se situa a 1.340 m da "praia” no rio Tapajós.

$\mathrm{Na}$ atividade de escavação, o valor negativo acumulado do impactos foi menor (-72), sendo que o elementos ambiental mais impactos foi o ar (-18). Isso já era esperado, posto que houve necessidade de revolvimento das camadas do solo, para formação do sulco receptor das anilhas de concreto e, para isso, a escavadeira, movida a óleo diesel, liberou enxofre (S) para o ar atmosférico. Sobre a manipulação do solo, Rezende e Coelho (2015), alertaram para o fato de que o início ou aceleração de processos erosivos ocorrem com a realização de desmatamentos no momento dos trabalhos de terraplenagem, em especial quando realizada nos locais mais sensíveis e se forem executados no período do ano de maior pluviosidade.

Quanto a terceira atividade, aplicação do piche, no meio físico, o solo e o ar atmosférico foram igualmente impactados (-14). A fabrico móvel do piche que necessita de altas temperaturas para manter essa substância no estado semissólido, eleva a temperatura local e libera substâncias tóxicas para o meio como, por exemplo os hidrocarbonetos policíclicos aromáticos (HPA’s) que são extremamente cancerígenos. Fernandes et al. (2014) e Oliveira et al. (2020), realizaram pesquisas acerca da pavimentação asfáltica e concluiram que há comprometimento da drenagem superficial e da qualidade da água subterrâneas, além disso, os rejeitos dessas ações tem interferência também na qualidade das águas superficiais que poderá ocorrer durante a fase de construção, como efeito do carreamento de sólidos, assoreamento da rede de drenagem, além da utilização de banheiros, cozinhas e refeitórios e outras estruturas de apoio às obras como as usinas de asfalto e centrais de britagem.

Quanto aos valores para magnitude (M) e importância (I) no meio físico, a análise dos dados obtidos indicou que eles não apresentaram intensidade elevada e a maioria deles são reversíveis (Quadro 2). 
Quadro 2. impactos potenciais identificados, valorados e qualificados no meio físico, Bairro Maracanã. Santarém, Pará.

Fonte:

\begin{tabular}{|c|c|c|c|c|c|c|c|c|c|c|c|c|c|}
\hline \multicolumn{5}{|c|}{ Atributos } & \multicolumn{9}{|c|}{ Potenciais } \\
\hline \multicolumn{3}{|c|}{$\mathbf{M}$} & C & I & \multicolumn{9}{|c|}{ Atributos } \\
\hline \multicolumn{3}{|c|}{$\leq+6 \mathrm{a} \geq+10$} & $\mathbf{A}$ & $\leq+6 a \geq+10$ & \multirow{8}{*}{ 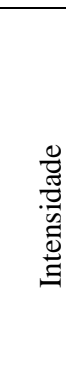 } & \multirow{8}{*}{$\frac{\stackrel{0}{0}}{\frac{0}{ \pm I}}$} & \multirow{8}{*}{ 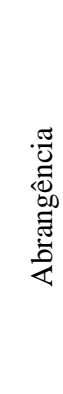 } & & \multirow{8}{*}{ 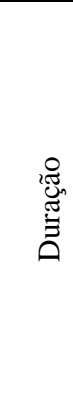 } & \multirow{8}{*}{ 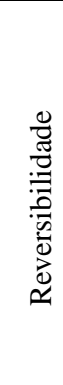 } & \multirow{8}{*}{$\begin{array}{l}\text { Ñ } \\
\stackrel{\Xi}{\Xi} \\
\text { Z }\end{array}$} & \multirow{8}{*}{ 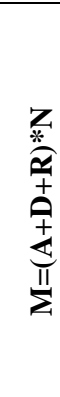 } & \multirow{8}{*}{ 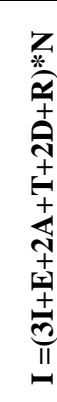 } \\
\hline \multicolumn{3}{|c|}{$\leq+1$} & B & $\leq+1$ & & & & & & & & & \\
\hline \multirow{2}{*}{\multicolumn{3}{|c|}{$\leq \pm 2 \mathrm{a} \leq \pm 5$}} & $\mathbf{M}$ & $\leq \pm 2 \mathrm{a} \leq \pm 5$ & & & & & & & & & \\
\hline & & & \multicolumn{2}{|c|}{ Legendas } & & & & \multirow{5}{*}{ 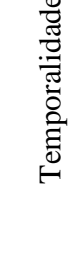 } & & & & & \\
\hline \multirow{2}{*}{\multicolumn{5}{|c|}{$\frac{\mathrm{M}=\text { Magnitude }}{\mathrm{C}=\text { Classificacão }}$}} & & & & & & & & & \\
\hline \multirow{2}{*}{\multicolumn{5}{|c|}{ I = Importância }} & & & & & & & & & \\
\hline & & & & & & & & & & & & & \\
\hline \multicolumn{5}{|c|}{$\mathrm{A}=$ alto $; \mathrm{B}=$ Baixo; $\mathrm{M}=$ Médio } & & & & & & & & & \\
\hline & C.A & & $\begin{array}{l}\text { men } \\
\text { bie }\end{array}$ & & 1 & 2 & 3 & 4 & 5 & 6 & 7 & & \\
\hline \multirow{10}{*}{ 递 } & \multirow{4}{*}{$\stackrel{\frac{\pi}{50}}{\frac{50}{4}}$} & & orea & ento & $-9,0$ & $-4,8$ & $-4,8$ & $-4,8$ & $-4,7$ & $-4,7$ & -1 & 1,4 & 6,0 \\
\hline & & & $\begin{array}{l}\text { lida } \\
\text { erfic }\end{array}$ & $\begin{array}{l}\text { das águas } \\
\text { is }\end{array}$ & $-9,4$ & $-5,2$ & $-5,2$ & $-5,2$ & $-5,1$ & $-5,0$ & -1 & 1,5 & 6,4 \\
\hline & & & $\begin{array}{l}\text { lida } \\
\text { errâ }\end{array}$ & $\begin{array}{l}\text { das águas } \\
\text { eas }\end{array}$ & $-4,7$ & $-4,0$ & $-4,0$ & $-4,0$ & $-3,9$ & $-3,8$ & -1 & 1,1 & 4,2 \\
\hline & & & & ento do lençol & -1 & $-4,3$ & $-4,3$ & $-4,3$ & $-4,2$ & $-4,2$ & -1 & 1,3 & 3,3 \\
\hline & \multirow{3}{*}{$\begin{array}{l}\circ \\
\text { in }\end{array}$} & & $\mathrm{raç}$ & da qualidade & $-5,1$ & $-4,4$ & $-4,4$ & $-4,4$ & $-4,3$ & $-4,3$ & -1 & 1,3 & 4,6 \\
\hline & & & tpa & ção & $-5,6$ & $-3,2$ & $-3,2$ & $-3,2$ & $-3,1$ & $-3,0$ & -1 & 0,9 & 3,9 \\
\hline & & & $\begin{array}{l}\text { içãc } \\
\text { ivo }\end{array}$ & e processos & $-3,0$ & $-2,5$ & $-2,5$ & $-2,5$ & $-2,4$ & $-2,4$ & -1 & $\mathbf{0 , 7}$ & 3,6 \\
\hline & \multirow{3}{*}{ 文 } & & $\begin{array}{l}\text { raç } \\
\text { são }\end{array}$ & $\begin{array}{l}\text { do nível de } \\
\text { nora }\end{array}$ & $-2,3$ & $-3,1$ & $-3,1$ & $-3,1$ & $-3,0$ & $-3,0$ & -1 & $\mathbf{0 , 9}$ & 2,8 \\
\hline & & & ssãc & le gases & $-2,0$ & $-3,0$ & $-3,0$ & $-3,0$ & $-2,9$ & $-2,9$ & -1 & 0,9 & 2,7 \\
\hline & & & eria & articulado & $-2,2$ & $-2,6$ & $-2,6$ & $-2,6$ & $-2,5$ & $-2,5$ & -1 & 0,8 & 2,4 \\
\hline
\end{tabular}

Autores (2021).

Para os impactos identificados, valorados e qualificados no Quadro 2, no meio físico, e em face dos níveis (médiobaixo), são sugeridas medidas mitigatórias, de curo e médio prazo:

1) Quanto a água, um estudo prévio da profundidade do lençol freático e o tipo de solo via granulometria para se estabelecer o máximo de carga possível que sobre ele pode ser exercida sem que haja aprofundamento do lençol freático;

2) verificação da taxa de infiltração da água no solo, para identificar se houve alteração entre o início, o desenrolar e o final da obra;

3) quanto a pressão sonora, verificar a possibilidade de manutenção de vegetação arbórea de grande e médio porte, com copas espessas que poderão ser utilizadas como barreiras sonoras.

4) a emissão gasosa pode ser controlada o uso de filtros na saída para ar nas máquinas de terraplanagem.

5) a emissão de partícula, deve ser evitada, especialmente no deslocamento de massa de solo oriunda da terraplanagem e transporte via caçambas, que deverão estar cobertas (capacete) com lonas adequadamente presas à fuselagem delas.

\section{Meio Biótico}

Outro CA com maior incidência de impacto: $n=-170$. Dois elementos ambientais foram os mais impactados, afugentamento e alteração da dinâmica populacional $(n=-24)$. Para melhor identificar a propor medidas a serem aplicadas para o meio biótico, fez-se a valoração e classificação dos seis atributos que permitiram a mensuração dos impactos ambientais causados nas três operações (Terraplanagem, escavações e aplicação de piche) pesquisadas (Quadro 3). 
Quadro 3. impactos potenciais ocorridos no meio biótico. Bairro Maracanã. Santarém, Pará.

\begin{tabular}{|c|c|c|c|c|c|c|c|c|c|c|c|c|}
\hline \multicolumn{13}{|c|}{ Potenciais } \\
\hline \multicolumn{4}{|c|}{ Atributos } & \multicolumn{9}{|c|}{ Atributos } \\
\hline & & $\mathbf{C}$ & I & \multirow{9}{*}{ 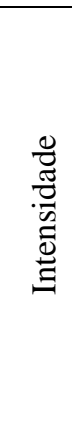 } & \multirow{9}{*}{$\underbrace{\stackrel{0}{0}}_{\frac{0}{0}}$} & \multirow{9}{*}{ 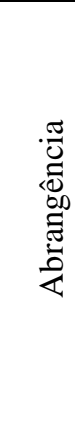 } & \multirow{9}{*}{ 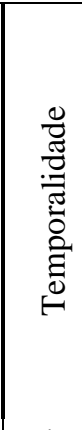 } & \multirow{9}{*}{ 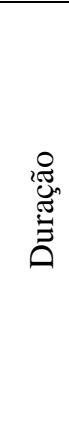 } & \multirow{9}{*}{ 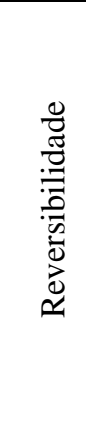 } & \multirow{9}{*}{$\begin{array}{l}\underset{N}{\mathbb{N}} \\
\stackrel{\Xi}{\Xi} \\
\text { Z }\end{array}$} & \multirow{10}{*}{ 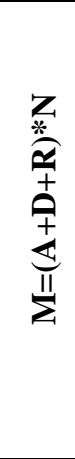 } & \multirow{10}{*}{ 落 } \\
\hline$\leq+$ & +10 & $\mathbf{A}$ & $\geq-1 a \leq-5$ & & & & & & & & & \\
\hline & & B & $\geq-10$ & & & & & & & & & \\
\hline$\leq \pm$ & $\leq \pm 5$ & $\mathbf{M}$ & $\geq-6 a \leq-9$ & & & & & & & & & \\
\hline \multicolumn{4}{|c|}{ Legendas } & & & & & & & & & \\
\hline \multirow{2}{*}{\multicolumn{4}{|c|}{$\begin{array}{c}\mathrm{M}=\text { Magnitude } \\
\mathrm{C}=\text { Classificação }\end{array}$}} & & & & & & & & & \\
\hline & & & & & & & & & & & & \\
\hline \multirow{2}{*}{\multicolumn{4}{|c|}{$\begin{array}{c}\mathrm{I}=\text { Importância } \\
\mathrm{A}=\text { alto; } \mathrm{B}=\text { Baixo; } \mathrm{M}=\text { Médio }\end{array}$}} & & & & & & & & & \\
\hline & & & & & & & & & & & & \\
\hline \multirow{9}{*}{ 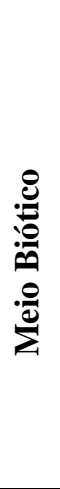 } & \multirow{6}{*}{$\underset{\Xi}{\overparen{\Xi}}$} & \multirow{2}{*}{\multicolumn{2}{|c|}{ Perda de individuos }} & 1 & 2 & 3 & 4 & 5 & 6 & 7 & & \\
\hline & & & & -3.0 & $-3,0$ & -2.9 & -2.8 & -2.7 & -2.6 & -1 & 9.4 & $\mathbf{1 0 , 0}$ \\
\hline & & \multicolumn{2}{|c|}{ Risco de acidentes } & -3.3 & -3.2 & -3.2 & $-3,0$ & -2.9 & -2.8 & -1 & 10,0 & $-13,7$ \\
\hline & & \multicolumn{2}{|c|}{ Afugentamento } & -3.3 & -3.2 & -3.2 & $-3,0$ & -2.9 & -2.8 & -1 & 10,0 & $-13,7$ \\
\hline & & \multicolumn{2}{|c|}{$\begin{array}{l}\text { Alteração das comunidades } \\
\text { aquáticas }\end{array}$} & -2.9 & -2.8 & -2.8 & -2.6 & -2.5 & -2.4 & -1 & 8.3 & $-8,8$ \\
\hline & & \multicolumn{2}{|c|}{$\begin{array}{l}\text { Alteração da dinâmica } \\
\text { populacional }\end{array}$} & -3.7 & -3.6 & -3.6 & -3.4 & -3.3 & -3.2 & -1 & 9.3 & $-19,6$ \\
\hline & \multirow{3}{*}{$\frac{\pi}{\frac{\pi}{2}}$} & \multicolumn{2}{|c|}{ Perda de individuos } & -3.3 & -3.2 & -3.2 & $-3,0$ & -2.9 & -2.8 & -1 & 9.1 & \\
\hline & & \multicolumn{2}{|c|}{ Pressão sobre habitats } & -3.2 & -3.0 & -3.0 & -2.9 & -2.8 & -2.7 & -1 & 8.7 & $-11,6$ \\
\hline & & \multicolumn{2}{|c|}{ Diminuição da fotossíntese } & -3.7 & -3.3 & -3.3 & -3.0 & $-3,0$ & -2.9 & -1 & 8.8 & $-18,1$ \\
\hline
\end{tabular}

Fonte: Elaborado pelos autores a partir dos dados por eles obtidos (2012).

O fator que incrementou isso foi a supressão vegetal provocada pela "limpeza" para a ocorrência da terraplanagem, tanto na rua de acesso ao conjunto (Figura 6a) quanto na primeira delas (Figura 6b). Isso provocou "alagamentos" durante o período chuvoso e pode ter ocorrido infiltração e percolação que não foram objetos dessa pesquisa, mas alerta-se para o fato de que deve ocorrer um estudo acerca dessas fatos antes que haja alagamentos mais efetivos que contribuam para a perda da qualidade de vida daquela comunidade.

Figura 6. a) via de acesso ao bairro Maracanã, rua Araruama; b) via de acesso às residências, Rua Ponta de Pedras. Bairro Maracanã, Santarém, Pará.

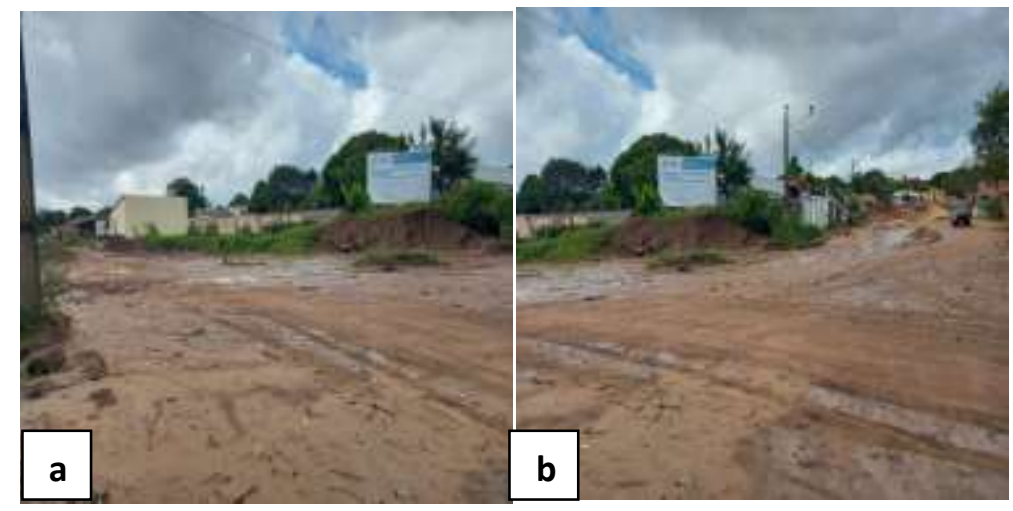

Fonte: Autores (2021). 
Acerca da degradação florestal, Carvalho et al. (2021) e Lopes e Longo (2020), realizaram pesquisas em Bocaina-PI, e em Campinas-SP, respectivamente. Os dados que eles obtiveram indicaram que as áreas de florestas estão sob forte pressão antrópica e, com isso, ocorrem perda de habitat, diminuição do fluxo gênio, isso tanto no meio urbano quanto no rural. No bairro Maracanã, nota-se que houve supressão vegetal, especialmente nas áreas de acesso, e isso é um dos fatores que intervém, de forma direta, no afugentamento das espécies, sejam arbóreas ou terrícolas.

Sobre a manutenção do verde urbano, Silveira et al. (2019) e Lins et al. (2019), efetuaram estudo sobre áreas verdes urbanas no município de São José-SC, e em Recife-PE, respectivamente. Eles concluiram que há uma quantificação mínima dessas áreas para que se possa classificá-las como "áreas verdes”, e uma dessas quantificações pode ser através do número de jardins, especialmente em áreas residenciais, fechadas ou abertas, e que isso corrobora para haja afugentamento da fauna, já que não respeitadas as coberturas vegetais que abrigam a fauna local. Nesse aspecto, o bairro Maracanã não apresenta tal condição.

Após a apuração da qualificação da magnitude e importância dos impactos identificador, pôde-se elaborar ações para mitigar os impactos ambientais negativos. Nesse contexto, sugere-se que:

1) Antes da terraplanagem e demais ações as empresas terceirizadas promovam um inventário florestal e biológico, na área onde será efetuada a atividade, especialmente a fauna arborícola e terrícola;

2) verificar a ocorrência de ninhos e marcar a vegetação onde estão como não disponíveis à supressão;

3) Determinar uma rota mais adequada à construção e/ou pavimentação asfáltica, para preservação conservação da fauna e flora.

4) outra sugestão está na criação de um banco de germoplasma para promoção de uma restauração florestal, o gestão dele pode ser de responsabilidade das instituições de ensino superior existentes no município de Santarém.

\section{Meio Antrópico}

A análise dos dados obtidos para esse meio, indicou que a magnitude apresentou impactos negativos baixos $(n=5,0)$, mas ocorreram também aqueles classificados como alto $(n=2,0)$, além de alterar o valor da terra (Quadro 4). 
Quadro 4. impactos potenciais no meio biótico. Bairro Maracanã. Santarém, Pará.

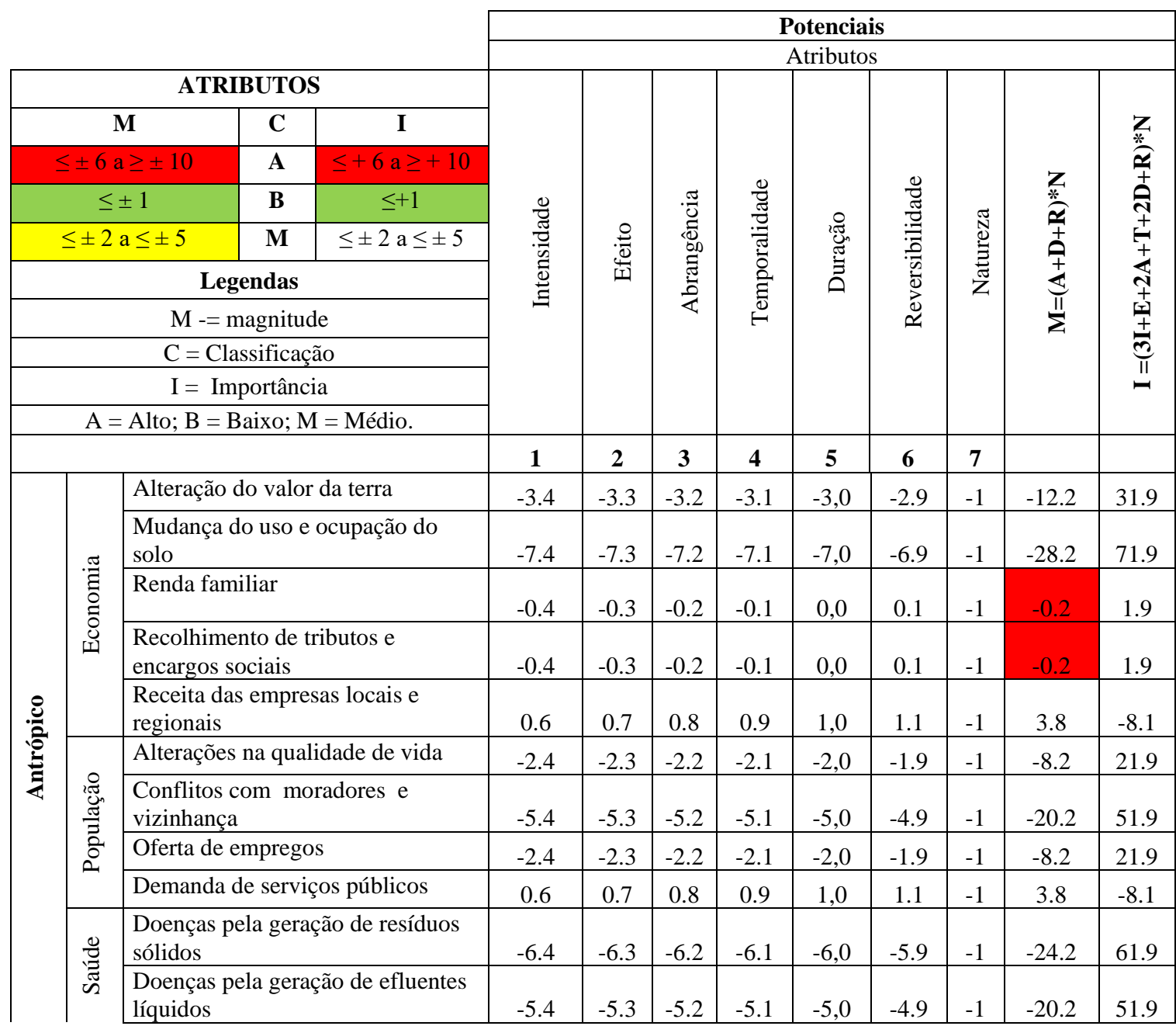

Fonte: Elaborado pelos autores a partir dos dados por eles obtidos (2012).

No Quadro 4 observa-se que o meio antrópico, no elemento ambiental saúde apresenta elevada importância (61.9; 51.9) em detrimento do baixa incidência dos impactos ambientais $(-24,2 ;-20,2)$, até o momento dessa pesquisa, dos impactos causados pelos resíduos sólidos e liberação de efluentes líquidos. Na economia, os impactos negativos são extremante elevados $(-0,2)$, isso pode estar associado a vias de acesso em terraplanagem, aos alagamentos e a formação de poças d'água formadas nas duas avenidas de acesso ao bairro. Outro impacto severo, foi a não utilização da mão-de-obra local, o que, em plena crise pandêmica, piora ainda mais o renda familiar daquela comunidade.

Na pesquisa pioneira efetuada por Mori (1994) em São Paulo-SP, ele concluiu que a implantação da infraestrutura garante às atividades do cotidiano, um desempenho mais livre de obstáculos como, por exemplo, vias com lama e escorregadias. Dentre essas "modernidades" o autor cita a melhoria nos transportes, melhoras no espaço econômico, dentre outros. Todavia, no bairro Maracanã a economia apresenta uma involução. Então estudos futuros poderão confirmar ou refutar a exposição ofertada por esse autor. Já no estudo efetuado por Salomão e Hirle (2019), no Vale do Mucuri-MG, e Assunção e Conceição (2018) em Criciúma-SC, eles concluiram que a construção de vias pavimentadas gera impactos tanto positivos como negativos e que isso pode gerar empregos aos moradores locais, além de problematizar as relações entre a casa, a rua. No primeiro relato, esse fato não foi observado no bairro Maracanã, mas no segundo caso, sim, houve um incremento nos conflitos intervizinhos, ainda de baixo impacto.

Para as medidas mitigatórias de caráter corretivas são: 
1) Fiscalização do Ministério Público, na esfera estadual, acerca da ganância econômica que irá se instalar após a conclusão, ou durante as atividades de infraestrutura no bairro, em associação com o sindicato dos corretores de imóveis, regional Santarém.

2) Promover um levantamento cadastral quanto ao uso e ocupação do solo, das unidades arquitetônicas residências, comercial ou mistas, para que náo haja implantação de quaisquer naturezas de comércios advindos de outros locais e utilizem o solo de forma inadequada como, por exemplo, pousadas, hotéis, e demais atividades oportunistas.

3) Ofertas vagas de emprego à comunidade local. Se ela não for capacitada, ofertar cursos de capacitação e permitir com que eles tenham vagas inclusivas no projeto de infraestrutura onde residem.

4) Atuar junto com a vigilância sanitária do município no sentido de mapear a ocorrência de doenças respiratórias, alérgicas ou não, bem como aquelas provocadas por ingestão de água contamina, para monitoramento das tendências de evolução durante e até ao término da obra. Em caso de aumento de casos relatados após o início da obra, promover um programa de assistência médica temporária evitar o agravamento da patologia.

\section{Conclusão}

Os impactos ambientais estão ocorrendo no bairro Maracanã, alguns já com intensidade elevada como, por exemplo, perda da vegetação, riscos de acidentes, incremento nos riscos de erodibilidade, dentre outros. As medidas mitigatórias preventivas não foram empregadas desde o início da obra, e isso permitiu a identificação, classificação e dos impactos ambientais existentes até o início dessa pesquisa. Todavia, se as medidas mitigatórias corretivas forem implantadas, é de bom alvitre que se realiza uma nova pesquisa com os dados contidos nesse documento para verificação das tendências de elevação, controle e ou diminuição dos impactos ambientais identificados, especialmente quanto ao fluxo do escamento superficial que desaguam no rio Tapajós.

\section{Referencias}

Amorim, M. C. C. T. (2020). Ilhas de calor urbano em cidades de pequeno e médio porte no Brasil e o contexto das mudanças climáticas. Revista FrancoBrasileira de Geografia, (46). https://journals.openedition.org/confins/31403\#: :text=A\%20análise\%20da\%20variabilidade\%20horária,a $\% 20$ gravidade $\% 20$ dos $\% 20$ resultados $\% 20$ diagnosticados $\% 2 \mathrm{C}$

Araújo, L. O, Cunha Neto, E. M., Melo, M. R. S, Santos, N. F. A \& Borges, L. S. (2020). Ação antrópica na incidência dos focos de calor na microrregião de Paragominas, estado do Pará, norte do Brasil. Revista Brasileira de Gestão Ambiental e Sustentabilidade, 7(17), 1153-1164, http://revista.ecogestaobrasil.net/v7n17/v07n17a08a.html. Doi: https://dx.doi.org/10.21438/rbgas(202)07108.

Assunção, V. K, \& Conceição, Z. S. (2018). Verticalização e sociabilidade: as relações entre moradores de edifícios residenciais e suas formações de uso e apropriação do espaço. Raega, (44,)69-84. https://revistas.ufpr.br/raega/article/view/47897\#: :text=0\%20processo\%20de\%20verticalização\%20avança,as\%2 Orelações\%20entre\%20seus\%20moradores.\&text=A\%20investigação\%20buscou\%20compreender\%20os,formas\%20de\%20habitação\%20e\%20vizinhança.

Bezerra, C, M, Farias, G. L, \& Gomes, A. C. A (2021). Análise espaço-temporal do uso e ocupação na Lagoa da Itaperaoba no bairro Serrinha em FortalezaCE. Cadernos de Ciências \& Tecnologia, 2(4), 9-27. https://revistas.uece.br/index.php/CCiT/article/view/4848

Carneiro, C. R. O, \& Terra, I. A. (2020) Ações antrópicas em períodos sazonais e problemas gerados ao meio ambiente na praia do Chapéu-Virado - Ilha do Mosqueiro (PA). Revista Cocar, 14, (29),328-347, 2020. https://periodicos.uepa.br/index.php/cocar/article/view/3375

Carvalho, F. A, Araújo, W. F, Sá, A, A, Sousa, J. J, S, Feitosa, R, N, \& Sousa, J. A. M. (2021). A interferência da ação antrópica na modificação do cenário urbano no município de Bocaina-PI. Educação Ambiental em Ação, (67). https://www.revistaea.org/artigo.php?idartigo=3571\#: :text=A\% 20INTERFERÊNCIA\%20DA\%20AÇÃO\%20ANTROPICA,NO\%20MUNICÍPIO\%20DE\%20BOCAINA-PI\&text=Resumo

$\% 3 \mathrm{~A} \% 20 \mathrm{Com} \% 20 \mathrm{a} \% 20$ necessidade $\% 20 \mathrm{de}$,sejam\%20elas\%20pequenas $\% 20 \mathrm{ou} \% 20$ grandes.

Correa, R. H, Vazquez, G. H, \& Vanzela, L. S. (2018). Projeto estratégico de ocupação do fundo de vale do córrego da Aldeia no perímetro urbano de Fernandópolis/SP. Revista Brasileira de Gestão Urbana, 10(2), 458-472. https://www.scielo.br/j/urbe/

Fernandes, M. L. F, Ramos, M, Tolentino, \& M, Fofonka, L. (2014). Impermeabilização excessiva do solo: impactos ambientais negativos. Revista Educação Ambiental, (49), https://www.revistaea.org/artigo.php?idartigo=1886\#: :text=Afundamento\%20de\%20terreno\%2C\%20ruindo\%20em,e $\% 20 \mathrm{re}$ síduos\%20sólidos\%20em\%20deterioração. 
Fonseca, W. A, Assunção, M. K. M, \& Silva, W. C. T (2020). Ponderação de impactos ambientais de obras de terraplanagem. Semana Academica,1, https://semanaacademica.org.br/artigo/ponderacao-de-impactos-ambientais-de-obras-de-terraplenagem\#: :text=Foi\%20possível\%20observar\%20qu e\%20 s, dimin uir\%20os\%20problemas\%20já\%20gerados.

Giacometti, K, \& Pilão, V. (2018). Ações antrópicas e impactos ambientais: industrialização e globalização. 2018. https://repositorio.uninter.com/bitstream/handle/1/108/Kerly\%20de\%20Giacometti.pdf?sequence=1\&isAllowed=y.

Gouveia, M. A. O. (2019). Asfalto drenante: proporções granulométricas e aplicabilidade. Trabalho de Conclusão de Curso. Instituto Federal Goiano. Goias. https://repositorio.ifgoiano.edu.br/handle/prefix/559.

Hatje, V, Cunha, L. C, \& Costa, M. F. (2018) Mudanças globais, impactos antrópicos e o futuro dos oceanos. Revista Brasileira de Química, 10(6), 19471967. http://rvq.sbq.org.br/detalhe_artigo.asp?id=1000

IBGE. Instituto Brasileira de Geografia e Estatística. Cidades. 2020. https://cidades.ibge.gov.br/brasil/pa/santarem.

Kaiser, E. A, Osto, J. V. D, \& Facco, D. S. (2017). Influência da ação antrópica sobre os processos erosivos e solapamento de margens no bairro Nova Santa marta e Vila bela Vista, Santa Maria - RS. In: Simpósio Brasileiro de Geografia Física Aplicada. São Paulo. Anais eletrônicos. https://www.revistas.usp.br/rdg/issue/view/9752.

Lima, R. C, Vieira, V. M, Costa, C. A. N, Viana, A. S. (2017). Análise comparativa dos impactos ambientais gerados na utilização de dois diferentes ligantes asfálticos no processo de pavimentação de estradas. Revista Eletrônica de Energia, 6(1), 4-17. https://revistas.unifacs.br/index.php/ree/article/view/3655

Lima, R. P. (2016). A ação antrópica como propulsora das mudanças climáticas na região nordeste. Revista Tocantinense de Geografia, (008), (91-102). http://www.bibliotekevirtual.org/index.php/2013-02-07-03-02-35/2013-02-07-03-03-11/1945-rtg/v05n08/20134-a-acao-antropica-como-propulsora-dasmudancas-climaticas-na-regiao-nordeste.html

Lins, E. A. M. (2019). Análise dos impactos Ambientais em uma rodovia - estudo de caso da PE - 063. In: Congresso Sulamericano de Resíduos Sólidos e Sustentabilidade. 2. 2019. Anais eletrônicos. http://www.ibeas.org.br/conresol/conresol2019/XV-060.pdf.

Lopes, D. C, \& Longo, R. M. (2020). Avaliação de aspectos ambientais limitantes a implantação e conservação de corredores ecológicos no município de Campinas/SP: estudo de caso no corredor ecológico da Mata de Santa Genebra. Cidades Verdes, 08(18),52-63. https://publicacoes.amigosdanatureza.org.br/index.php/cidades_verdes/article/view/2518/0

Lopes, J. L. (2008). Riscos para a saúde de trabalhadores de pavimentação com asfalto. Interfacehs, 3(3), 2-10. http://www3.sp.senac.br/hotsites/blogs/InterfacEHS/wp-content/uploads/2013/07/inter-1-2008-3.pdf

Matos, F. B, Luna, V. F, \& Oliveira, J. M. (2019). Caracterização de impactos ambientais no bairro São José, em Juazeiro do Norte/CE. In: Simpósio Brasileiro de Geografia Aplicada. Anais eletrônicos. http://www.editora.ufc.br/images/imagens/pdf/geografia-fisica-e-as-mudancas-globais/1205.pdf.

Martins, T. S, \& Carmo Júnior, G. N. R. (2018). Avaliação de Impacto Ambiental: uma revisão sistemática sob a ótica metodológica. Engineering and Science, 7(2),29-41. https://periodicoscientificos.ufmt.br/ojs/index.php/eng/article/view/6616

Microsoft Corporation. Excel, versão 2013. https://www.microsoft.com/pt-br/microsoft-365/previous-versions/microsoft-excel-2013.

Morales, G. P, Ribeiro, H. M. P, \& Vera, M. A. P. (2015). Aplicação de check list quantitativa para avaliar os impactos ambientais nos meios físico, biológico e antrópico causados pelas ocupações irregulares - estudo de caso ocupação chico mendes. Revista SODEBRAS, 10(113), 40-44, 2015. http://www.sodebras.com.br/edicoes/N113.pdf

Mori, K. A. K. (1994). Estudo de impacto ambiental de infraestruturas urbanas uma questão de princípios. Paisagem Ambiente Ensaios, 6(47), 1994. https://www.revistas.usp.br/paam/article/view/133795/129663

Oliveira, L. J. C, Soares, M. C. B, Quaresma, W. M. G, \& Adorno, A. L. C. (2020). Gestão de resíduos: uma análise sobre os impactos da geração de rejeitos na construção civil. Brazilian Journal of Development, 6(5), 24447-24462. https://www.brazilianjournals.com/index.php/BRJD/article/view/9550

Ono, B. W, Balbo, J. T, \& Cargnin, A. P. (2017). Análise da capacidade de infiltração em pavimento permeável de bloco de concreto unidirecionalmente articulado. Transporte, 25(2), 9-101. https://www.revistatransportes.org.br/anpet/article/view/1314

Pereira, A. S, Shitsuka, D. M, Parreira, F. J, \& Shitsuka, R. (2018). Metodologia da Pesquisa Científica. Santa Maria: UAB/NTE/UFSM, 2018. https://www.ufsm.br/app/uploads/sites/358/2019/02/Metodologia-da-Pesquisa-Cientifica_final.pdf

Rezende, E. N, \& Coelho, H. A. (2015). Impactos ambientais decorrentes da construção de estradas e suas consequências na responsabilidade civil, RDMV, 9(2), 155-180. https://portalrevistas.ucb.br/index.php/rvmd/article/view/5880

Rosa, G. M, Silva, F. R, \& Costa Júnior, J. A. C. (2021). Ações antrópicas e exploração dos recursos ambientais nomeio rural, no norte do RS: questões históricas, culturais e desafios para projetar novas atitudes. Research Society and Development, 10(10). https://redib.org/Record/oai_articulo3351684-açõesantrópicas-e-exploração-dos-recursos-ambientais-meio-rural-norte-do-rs-questões-históricas-culturais-e-desafios-para-projetar-novas-atitudes

Rosa, K. O. A. (2019). Avaliação de impacto ambiental em propriedades de agricultura familiar no Cerrado Brasileiro. Dissertação (Mestrado em Engenharia Aplicada e Sustentabilidade) - Instituto Federal de Educação, Ciência e Tecnologia. Goiás. https://sistemas.ifgoiano.edu.br/sgcursos/uploads/anexos_14/2021-08-19-03-27-37dissertação_Karynna\%20Rosa_Repositório.pdf

Salomão, P. E. A, \& Hirle, R. E. W. (2019). Estudo da influência das queimadas e banco de sementes dos solos do Vale do Mucuri. Research, Society, and Development, 8(12), 2019. https://www.redalyc.org/journal/5606/560662203038/html/

Sánchez, L. E. (2013). Avaliação de Impacto Ambiental. Conceitos e métodos. (2a ed.), Oficina de textos. 
Scalamanto, A. T, Garcia, M. S, Ochulacki, R. B, Pereira, T. S, \& Souza B. S, P. (2019). Ação antropogênica como agente nos processos geomorfológicos. BGG, 45(1-2),153-166. https://www.seer.ufrgs.br/bgg/article/viewFile/78189/55044\#: :text=O\%20homem\%2C\%20enquanto\%20agente\%20geom orfológico,parte $\% 20 \mathrm{de} \% 20 \mathrm{um} \% 20$ sistema\%20inacabado.

Silva, L. F, Souza, B. I, \& Bacani, V. M. (2019). Intensidade da ação antrópica na área de Proteção Ambiental do Cariri Paraibano. Caminhos da Geografia, 20(71), 364-383. http://www.seer.ufu.br/index.html\#: :text=O\%20resultado\%20culminou\%20em\%20cinco,Alta\%20(21\%2C47\%25).

Silva, M. F. (2020). A degradação ambiental decorrente da construção do ramal de Água Preta/Areal, zona rural de Manaus, Amazonas. Dissertação (Mestrado em Geografia Física). - Universidade Federal do Amazonas, Manaus. https://tede.ufam.edu.br/handle/tede/8091

Silva, P. M. B. M, \& Silva, M. M. (2020). Igarapés impactados pela ação antrópica no município de Uruará. Enciclopédia Biosfera, 17(31),103-114. http://www.conhecer.org.br/enciclop/2020A/igarapes.pdf

Silveira, S. J, Oliveira, F. H, Schuch, F. S. (2019). Área verde mínima para loteamento sustentáveis segundo o ciclo hidrológico. Arquitetura Revista, $16(1), 23-45$.

http://revistas.unisinos.br/index.php/arquitetura/article/view/arq.2020.161.02\#: :text=O\%20resultado\%20da\%20aplicação\%20do,ser\%20loteada\%20como\%2 0área\%20verde.

Sorte, M. D. B, \& Coêlho, M. W. S. (2019). O papel do pesquisador na metodologia de investigação cientifica: a importância da pesquisa cientifica qualitativa ou quantitativa. Multidisciplinary Scientif Journal Núcleo do Conhecimento, 09(10),102-111.2019. https://www.nucleodoconhecimento .com.br/educacao/papel-do-pesquisador

Souza, A. T, \& Mesquita, I. R. S. B. (2017). Ações antrópicas no espaço urbano e a proteção constitucional do meio ambiente. Revista Âmbito Jurídico, (159). https://ambitojuridico.com.br/cadernos/direito-ambiental/acoes-antropicas-no-espaco-urbano-e-a-protecao-constitucional-do-meio-ambiente/\#: :text=Açõ es $\% 20$ antrópicas $\% 20$ no $\% 20$ espaço $\% 20$ urbano $\% 20 \mathrm{e} \% 20 \mathrm{a} \% 20$ proteção\%20constitucional\%20do\%20meio\%20ambiente,-Por\%20Equip e\%20Âmbito \&text= A $\% 20$ cidade $\% 20 \mathrm{e} \% 20 \mathrm{o} \% 20$ urbano,e $\% 20$ com $\% 20 \mathrm{o} \% 20$ meio $\% 20$ ambiente.

Stamm, H. R (2003). Método para avaliação de impacto ambiental (AIA) em projeto de grande porte: estudo de caso de uma usina termelétrica. Tese (Doutorado em Engenharia de Produção) - Universidade Federal de Santa Catarina, Florianópolis. https://repositorio.ufsc .br/xmlui/handle/123456789/85357\#: :text=A-\%20A\%20A\%2B-,Método\%20para\%20avaliação\%20de\%20impacto\%20am biental\%20(AIA)\%20em\%2 0projetos\%20de,caso \%20de\%20uma\%20usina\%20termelétrica\&text=Resumo\%3A,a\%20manutenção\%20das\%20gerações\%20futuras.

Stefanuto, E. B, Zanatta, F. A. S, \& Lupinacci, C. M (2017). Análise histórica do uso da terra em antropogeomorfologia: alguns exemplos paulistas. Revista Brasileira de Geografia, 62(2), 95-112. https://dialnet.unirioja.es/servlet/articulo?codigo=7317657

Ufopa. Universidade Federal do Oeste do Pará. (2020). Histórias curiosas marcam origem de bairros de Santarém. http://www.ufopa.edu.br/comunicacao/comunica/jornalismo/ufopa-na-midia-2/2018/junho/historias-curiosas-marcam-origem-de-bairros-de-santarem/ 